\title{
Diagnóstico citológico de neoplasia pulmonar por meio de lavado broncoalveolar em uma cadela: relato de caso
}

[Cytologic diagnosis of pulmonary neoplasm with bronchoalveolar lavage in a bitch: case report]

\author{
P.E. Ferian ${ }^{1}$, E.F. Silva ${ }^{2}$, R.C. Guedes ${ }^{3}$, R.C.S. Tôrres ${ }^{3 *}$, R.A. Carneiro ${ }^{3}$ \\ ${ }^{1}$ Aluno de pós-graduação - EV-UFMG \\ ${ }^{2}$ Médico Veterinário - EV-UFMG \\ ${ }^{3}$ Escola de Veterinária - UFMG \\ Caixa Postal 567 \\ 30123-970 - Belo Horizonte, MG
}

\begin{abstract}
RESUMO
Relata-se o caso de uma cadela de raça Poodle, de 12 anos de idade, com quadro clínico de tosse crônica não responsiva à terapia medicamentosa. $\mathrm{O}$ exame radiográfico mostrou imagem de consolidação do lobo pulmonar esquerdo. O exame de lavado broncoalveolar pelo broncofibroscópio mostrou células epiteliais com características de malignidade, permitindo firmar o diagnóstico de carcinoma pulmonar sem diferenciação entre neoplasia primária ou metastática.
\end{abstract}

Palavras-chave: cão, lavado broncoalveolar, citologia, neoplasia

\begin{abstract}
This article reports a case of a bitch, Poodle, 12 year-old with chronic cough, which had insufficient response to medicamentous therapy. Thoracic radiographic revealed a lobar consolidation in left caudal pulmonary lobe. A bronchoalveolar lavage sample was collected by bronchoscopy for cytology examination. Malignant epithelial cells were observed through cytology allowing the diagnosis of carcinoma. The differential diagnosis between primary pulmonary neoplasm and metastatic neoplasm was not possible.
\end{abstract}

Keywords: dog, bronchoalveolar lavage, cytology, neoplasm

\section{INTRODUÇÃO}

As alterações pulmonares representam cerca de 4\% da casuística em clínica médica de pequenos animais. Os principais exames complementares utilizados em seu diagnóstico incluem a radiografia torácica, o lavado traqueal, o lavado broncoalveolar, a broncoscopia, a punção aspirativa transtorácica por agulha fina e a biópsia transtorácica ou com toracotomia (Hawkins et al., 1990; Rha e Mahoney, 1999;
Norris et al., 2001; Andreasen, 2003; Mello e Ferreira, 2003). No Brasil, no entanto, a maioria dos casos fica restrita à avaliação clínica e ao exame radiográfico.

A avaliação radiográfica do tórax é um exame amplamente utilizado, não invasivo e que fornece importantes informações diagnósticas. Contudo, processos infecciosos, parasitários, inflamatórios não infecciosos, alérgicos e neoplásicos no pulmão podem exibir o mesmo

Recebido para publicação em 14 de setembro de 2004

Aceito em 7 de dezembro de 2005

*Autor para correspondência (correspoding author)

E-mail: rtorres@vet.ufmg.br 
padrão de alteração radiográfica, dificultando o diagnóstico definitivo (Sutter, 1974; Nafe, 1979; Walter et al., 1984; Hawkins et al., 1990). Dessa maneira, a avaliação citológica pulmonar pode fornecer importantes informações acerca da etiologia do processo. Para esse tipo de avaliação, amostras respiratórias podem ser obtidas, em pequenos animais, por meio de lavado traqueal (transtraqueal ou transoral), lavado bronco-alveolar (LBA) (broncoscopia e sonda endotraqueal) e punção aspirativa por agulha fina (Burkhard et al., 2003).

O lavado traqueal é mais representativo das vias aéreas mais calibrosas, sendo limitado em relação às alterações das vias aéreas menos calibrosas e alvéolos. A aspiração transtorácica com agulha fina é um excelente método para se obter material do parênquima pulmonar, sendo mais valiosa quando se observa radiograficamente uma massa ou enfermidade difusa do parênquima. O LBA é uma técnica que consiste na infusão de solução de $\mathrm{NaCl}$ nos pulmões, por meio de broncoscópio ou sonda endotraqueal, para aspiração. O fluido obtido com o lavado pode ser submetido a avaliações microbiológicas, bioquímicas e citológicas (quantitativa e qualitativa). $\mathrm{O}$ exame qualitativo é fundamental, devendo-se observar fagocitose de bactérias ou hemácias por neutrófilos ou macrófagos, presença de neutrófilos degenerados, presença de estruturas fúngicas ou parasitárias e alterações celulares sugestivas de neoplasia (Bernard et al., 1980; Rebar et al., 1980; Vail et al., 1995; Burkhard et al., 2003).

Em relação às neoplasias, a avaliação citológica pode ser valiosa. As neoplasias pulmonares em cães podem ser de origem primária ou metastática, sendo as primárias raras $\mathrm{e}$ as metastáticas freqüentes. As principais neoplasias que ocasionam metástase pulmonar em cães são as mamárias, as ósseas e as prostáticas. Como citado anteriormente, as neoplasias também não exibem padrões radiográficos característicos, podendo ser confundidas com processos inflamatórios, infecciosos atípicos, fúngicos e parasitários. O LBA tem sido descrito como diagnóstico em neoplasias pulmonares primárias, como os linfomas pulmonares (apenas em humanos) e carcinomas e neoplasias metastáticas, como os linfomas multicêntricos, carcinomas diversos e leucemias (Levy et al., 1988; Kovalsky et al, 1990; Hawkins et al., 1993; Yohn et., al., 1994).

O objetivo deste trabalho é relatar o diagnóstico de neoplasia pulmonar em uma cadela por meio de avaliação citológica do fluido obtido do LBA com broncoscópio.

\section{CASUÍSTICA}

Uma cadela da raça Poodle, com 12 anos de idade, foi atendida no dia 21 de fevereiro de 2004, com quadro de tosse há cerca de um mês, tendo iniciado os sintomas após banho e tosa em estabelecimento veterinário. Já havia sido feito tratamento com amoxicilina (sete dias), pipazetato (três dias), N-aceticisteína (oito dias), clenbuterol (quatro dias) e benzidamida, sem que houvesse melhora significativa. $\mathrm{O}$ animal apresentava normorexia, normodipsia, normúria e normoquesia. As vacinas e vermifugações estavam atualizadas.

Ao exame clínico, observou-se presença de nódulos em glândulas mamárias, doença periodontal acentuada e sopro cardíaco sistólico grau $3 / 6$ em foco mitral. Os demais sistemas orgânicos estavam dentro da normalidade. Firmou-se diagnóstico provável de insuficiência cardíaca congestiva esquerda e colapso de traquéia. Foram requisitados, como exames complementares, radiografias latero-lateral e ventrodorsal de tórax e traquéia cervical e hemograma completo.

O exame radiográfico mostrou consolidação de lobo pulmonar caudal esquerdo com deslocamento de silhueta cardíaca (Fig. 1), levando à suspeita de neoplasia pulmonar, provavelmente primária, em função da característica radiográfica. $\mathrm{O}$ hemograma revelou leucocitose com desvio à esquerda regenerativo. Foi prescrito azitromicina $(10 \mathrm{mg} / \mathrm{kg}$, uma vez ao dia) e solicitado procedimento de broncoscopia com LBA para avaliação citológica. 


\section{Ferian et al.}
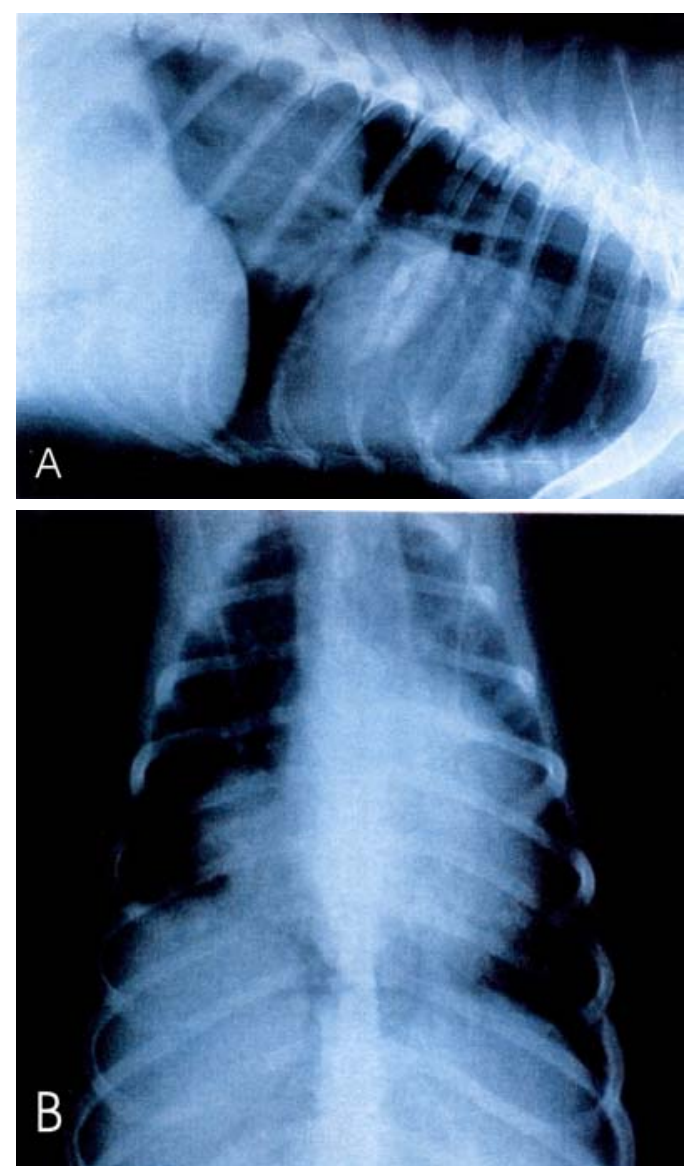

Figura 1. A. radiografia latero-lateral de tórax, evidenciando consolidação de lobo pulmonar caudal. B. projeção ventro-dorsal mostrando consolidação em lobo pulmonar esquerdo e deslocamento lateral direito de silhueta cardíaca.
Para a realização do exame, o animal foi prémedicado com acepromazina $(0,05 \mathrm{mg} / \mathrm{kgEV}) \mathrm{e}$ anestesiado com propofol $(5 \mathrm{mg} / \mathrm{kgEV})$. O paciente foi entubado, e o oxigênio fornecido através de sonda de PVC siliconizada acoplada à sonda endotraqueal. O broncofibroscópio foi passado através da sonda endotraqueal e direcionado ao brônquio principal direito e, por ele, avaliou-se a morfologia do lúmen dos lobos pulmonares direito, os quais se encontravam normais. O broncofibroscópio foi recolhido e, então, direcionado ao brônquio principal esquerdo. Nele observaram-se compressão brônquica acentuada e eritema difuso da mucosa brônquica. Instilaram-se duas alíquotas de $20 \mathrm{ml}$ de solução de $\mathrm{NaCl}$ a $0,9 \%$ no pulmão esquerdo, através do canal do broncofibroscópio, e realizou-se, após cada infusão, a aspiração do fluido. As amostras foram enviadas ao laboratório, sendo processadas pela técnica de câmara de sedimentação, conforme descrito por Freeman e Raskins (2003). As lâminas foram coradas com Maygrunwald-Giemsa. Ao exame citológico qualitativo, observaram-se cromatina frouxa, múltiplos macronucléolos (Fig. 2A), pleomorfismo de células justapostas com citoplasma amplo (Fig. 2B), certo amoldamento nuclear e algumas células binucleadas (Fig. 2C), sugerindo tratar-se de neoplasia epitelial maligna.
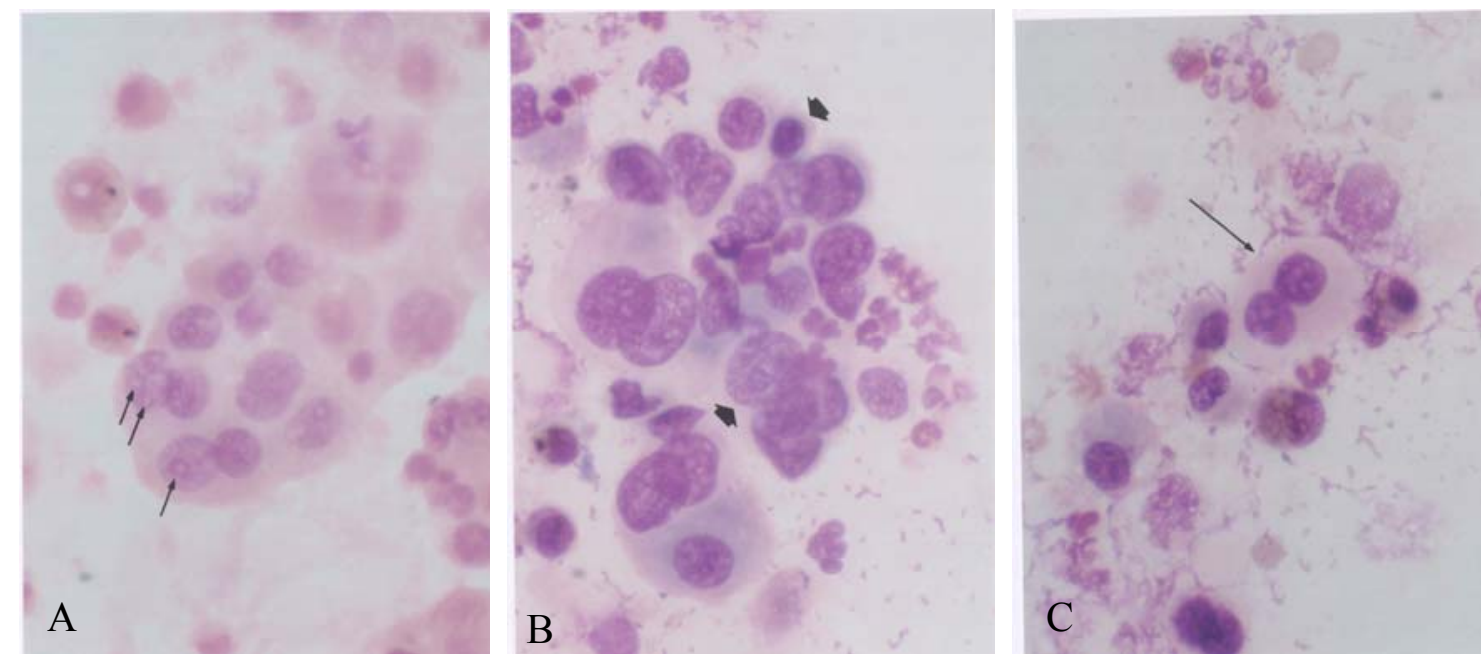

Figura 2. Micrografia de citologia de lavado broncoalveolar. A. células epiteliais justapostas com citoplasma eosinofílico amplo e macronucléolos múltiplos circulares ou ovóides (seta). B. pleomorfismo celular e ansiocariose evidentes. C. células binucleadas. 
Aproximadamente quatro meses depois (11/06), o paciente retornou ao hospital com quadro de angústia respiratória grave, sendo diagnosticado quadro de efusão pleural. Foi realizada a drenagem do líquido (cerca de 100ml), de aspecto sero-sanguinolento. Após poucos dias, ocorreu recidiva da efusão e piora do quadro respiratório, sendo requisitada a eutanásia pelo proprietário.

À necropsia, observou-se um nódulo no lobo pulmonar caudal esquerdo, de cerca de cinco centímetros de diâmetro, sem limites nítidos, de consistência firme, brancacento, com cavidade central repleta de exsudato purulento, com aderências em pleura parietal, diafragma e esôfago. Notou-se pleurite fibrino-hemorrágica difusa com exsudato fibrinoso na cavidade torácica. O coração apresentava-se com dilatação moderada. As mamas inguinais continham nódulos bilaterais, de um a três centímetros de diâmetro. O diagnóstico histológico do pulmão foi de carcinoma bronquíolo-alveolar. Nas mamas diagnosticaram-se adenoma, epitelioma sebáceo e adenoma complexo.

\section{DISCUSSÃO}

As neoplasias pulmonares primárias em cães são de ocorrência rara, principalmente quando comparadas às neoplasias metastáticas. $\mathrm{O}$ principal método utilizado na rotina clínica de pequenos animais para o diagnóstico de ambas é, sem dúvida, o exame radiográfico. Essa avaliação, aliada ao histórico e ao exame físico, fornece fortes indícios da presença de neoplasia pulmonar, sem, no entanto, oferecer diagnóstico definitivo, o qual só pode ser feito por meio de avaliações citológicas e/ou histológicas.

Algumas patologias, como infecções atípicas, parasitoses, pneumonia fúngica e afecções inflamatórias, podem mimetizar em grau surpreendente os padrões radiográficos neoplásicos.

Além disso, outras situações, como a existência de dois tumores primários em um mesmo paciente, podem levar à interpretação radiográfica errônea de lesões benignas. Brody e Craig (1965) observaram que, de 29 cães que apresentavam neoplasia pulmonar primária, 15 estavam com tumores em outros locais do corpo.
Nafe (1979) relatou casos de duas gatas que apresentavam tumores mamários e concomitante massa pulmonar em exame radiográfico, sendo um abscesso e um tumor primário de pulmões.

A avaliação citológica de amostras pulmonares pode ser valiosa para o diagnóstico de neoplasias pulmonares, além de ser um método menos invasivo que a avaliação histológica. Como todo método citológico, duas questões mostram-se particularmente importantes: qual a sensibilidade do método e em que extensão ele pode predizer as características histológicas da lesão? Vários relatos em medicina humana testaram a sensibilidade diagnóstica do LBA no diagnóstico de neoplasias pulmonares e sua relação com o exame histológico.

Linder et al. (1993) estudaram 35 pacientes com confirmação histológica de câncer pulmonar, dos quais $24(68,6 \%)$ foram confirmados pelo LBA e em $79,1 \%$ deles houve concordância entre cito e histopatologia. Johnston e Bossen (1981) estudaram 206 casos de neoplasias pulmonares primárias com exames cito e histológicos. A capacidade da citologia em predizer o tipo histológico da lesão variou de 26 a 95\%, de acordo com o tipo do tumor. Levy et al. (1988) relataram que, em cinco pacientes com metástase pulmonar de carcinomas diversos, todos foram considerados como positivos no LBA. É importante ressaltar que o examinador é uma importante fonte de variação, sendo fundamental um profissional com boa experiência em citopatologia.

Em medicina veterinária, os principais estudos foram realizados com linfoma multicêntrico. Hawkins et al. (1993) demonstraram em seu trabalho que o LBA detectou, em um grupo de 47 cães, $66 \%$ positivos para envolvimento pulmonar com linfoma contra apenas 33\% do exame radiográfico.

No presente relato, o paciente apresentava sintomatologia inespecífica de tosse não responsiva à terapia medicamentosa. A imagem radiográfica de consolidação lobar não foi suficiente para firmar um diagnóstico definitivo, requisitando-se a avaliação citológica do fluido obtido com o LBA. Os achados do exame possibilitaram o diagnóstico de neoplasia epitelial maligna (carcinoma). Deve-se esclarecer, no entanto, que não foi possível a 


\section{Ferian et al.}

diferenciação entre neoplasia primária e metastática, pois a cadela apresentava ao exame clínico nódulos mamários. A presença de infecção evidenciada por intensa leucocitose no hemograma e, posteriormente, confirmada pela necropsia é achado comum secundário a neoplasias pulmonares.

Estudos controlados com um número significativo de animais tornam-se necessários para avaliar a sensibilidade diagnóstica do método nas lesões pulmonares neoplásicas em medicina veterinária, possibilitando a utilização mais ampla do exame.

\section{CONCLUSÕES}

Neste caso, o exame citológico do LBA foi satisfatório em fornecer $\mathrm{o}$ diagnóstico de neoplasia pulmonar, sem diferenciar entre moléstia primária ou metastática.

\section{REFERÊNCIAS BIBLIOGRÁFICA}

ANDREASEN, B. C. Bronchoalveolar lavage. Vet. Clin. North Am.: Small Anim. Pract., v. 33, p. 69-88, 2003.

BERNARD, J.; GEE, L.; FICK Jr., R. Bronchoalveolar lavage. Thorax, v. 35, p. 1-8, 1980.

BRODY, R. S.; CRAIG, P. H. Primary pulmonary neoplasms in the dog: a review of 29 cases. J. Am. Vet. Med. Assoc., v. 147, p. 1628, 1965.

BURKHARD, M. J.; VALENCIANO, M.; BARGER, A. Sistema respiratório. In: RASKINS, R. E.; MEYER, D. J. Atlas de citologia de cães e gatos. São Paulo: Roca, 2003. p. 113-156.

FREEMAN, P. K.; RASKINS, R. E. Citologia do sistema nervoso central. In: RASKINS, R. E.; MEYER, D. J. Atlas de citologia de cães e gatos. São Paulo: Roca, 2003. p. 275-308.

HAWKINS, E. C.; DeNICOLA, D. B.; KUEHN, N. F. Bronchoalveolar lavage in the evaluation of pulmonary disease in the dog and cat. State Art. J. Vet. Int. Med., v. 4, p. 267-274, 1990

HAWKINS, E. C.; MORRISON, W. B.; DENICOLA, D. B. et al. Cytologic analysis of bronchoalveolar lavage from 47 dogs with multicentric malignant lymphoma. $J$. Am. Vet. Med. Assoc., v. 203, p. 1418-1425, 1993.

JOHNSTON, W. W.; BOSSEN, E. H. The cytopathological diagnosis of lung cancer during the years 1970 to 1974, with a comparison between cytopathology and histopathology in the typing of lung cancer. Acta Cytol., v. 25, p. 499-505, 1981.

KOVALSKI, R.; HANSEN-FLSCHEN, J.; LODATO, F. R.PI et al. Localized leukemic pulmonary infiltrates: diagnosis by bronchoscopy and resolution with therapy. Chest, v. 97, p. 674-678, 1990.

LEVY, H.; HORAK, D. A.; LEWIS, M. L. The value of bronchial washings and bronchoalveolar lavage in the diagnosis of lymphangitic carcinomatosis. Chest, v. 94, p. 1028-1030, 1988.

LINDER, J.; RADIO, S. J.; ROBBINS, R. A. et al. Bronchoalveolar lavage in the cytologic diagnosis of the carcinoma lung. Acta Cytol., v. 37, p. 796-801, 1993.

MELLO, M. F. V.; FERREIRA, A. M. R. Análise citológica do líquido da lavagem broncoalveolar para diagnóstico das doenças pulmonares caninas - revisão. Rev. Clin. Vet., n. 42, p. 52-58, 2003.

NAFE, L. A. Mammary tumors and unassociated pulmonary masses in two cats. J. Am. Vet. Med. Assoc., v. 175 , p. $1194,1979$.

NORRIS, C. R.; GRIFFEY, S. M.; SAMII, V. F. et al. Comparison of results of thoracic radiography, cytologic evaluation of bronchoalveolar lavage fluid, and histologic evaluation of lung specimens in dog with respiratory tract disease: 16 cases (1996-2000). J. Am. Vet. Med. Assoc., v. 218, p. 1456-1461, 2001

REBAR, A. H.; DeNICOLA, D. B.; MUGGENBURG, B. A. Bronchopulmonary lavage cytology in the dog: normal findings. Vet. Pathol., v. 17, p. 294-304, 1980.

RHA, J.Y.; MAHONY, O. Bronchoscopy in small animal medicine: indications, instrumentations, and techniques. Clin. Tech. Small Anim. Pract., v. 14, p. 207-212, 1999.

SUTER, P. F. Radiographic recognition of primary and metastatic pulmonary neoplasm of dogs and cats. Vet. Radiol. Soc., v.15, p. 3-25, 1974.

VAIL, D. M.; MAHLER, P. A.; SOERGEL, S. A. Differential cell analysis and phenotypic subtyping of lymphocyts in bronchoalveolar lavage fluid from clinically normal dogs. Am. J. Vet. Res., v. 56, p. 282-285, 1995.

WALTER, P.A; HAYNES, J. S.; FEENEY, D. A. et al. Radiographic appearance of pulmonary metastases from transitional cell carcinoma of the bladder and urethra of the dog. J. Am. Vet. Med. Assoc., v. 185, p.411-418, 1984.

YOHN, S.; HAWKINS, E. C.; MORRISON, W. B. et al. Confirmation of pulmonary component of multicentric lymphossarcoma with bronchoalveolar lavage in two dogs. J. Am. Vet. Med. Assoc., v. 204, p. 97-101, 1994. 